\title{
Agricultural Monitoring Using Satellite Data
}

\author{
Genya SAITO*, Izumi NAGATANI**, Shigeo OGAWA*** and Xianfang SONG**** \\ * Graduate School of Agricultural Science, Tohoku University, 1-1,Tsutsumidori Amamiya-machi \\ Aoba-ku, Sendai, 981-8555, Japan, E-mail genya@bios.tohoku.ac.jp \\ ** Computer Center for Agriculture, Forestry \& Fisheries Research, 2-1-9 Kannondai, Tsukuba, Ibaraki, \\ 305-8601, Japan,nagatani@affrc.go.jp \\ *** National Institute for Rural Engineering, 2-1-6 Kannondai, Tsukuba, Ibaraki, 305-8609, Japan, \\ sogawa@nkk.affrc.go.jp \\ **** Institute of Geographical Sciences \& Natural Resource Researches, CAS, \\ Building 917, Datun Road, Anwai, Beijing, 100101,China, songxf@igsnrr.ac.cn
}

\begin{abstract}
To use remote sensing techniques for agricultural monitoring, near-real time data acquisition, treatment, and distribution are necessary. For this reason, we are now developing Satellite Image Data Base System (SIDaB). First, we will introduce our SIDaB system, and our future plane of satellites data acquisition. Using network systems such as Asia Pacific Advanced Network (APAN), we get NOAA/AVHRR, TERRA\&AQUA/MODIS and DMSP/OLS data in near-real time.

Next, we will talk about the vegetation monitoring system. We are also developing an agriculture -monitoring system in East Asia using NOAA/AVHRR data. Every ten day, the maximum Normalized Difference Vegetation Index (NDVI) is compared with the past three years average of ten-day maximum NDVI values. The standard ten-day NDVI images are created using the ten-days data of 1997-1999. To reduce the cloud noise, the maximum value of NDVI is used for ten-day composites. When the average value is calculated, the negative NDVI pixels are eliminated, since there are cloud pixels even in ten-day composites. Then, the differences of the NDVI images between the standard ten-day NDVI images and up-to-date ten-day NDVI images are calculated. Using the differences, it is possible to detect the area of drought damage on agriculture. The nagative difference $(<-0.1)$ pixels are listed as drought risk areas in spring and summer.
\end{abstract}

Key words: Agricultural monitoring, East Asia, NOAA/AVHRR, Remote Sensing.

\section{INTRODUCTION}

In recent years, satellite, computer, and network technologies have been developed on a yearly basis, and have come to be used widely. NOAA satellites provide a regular, repetitive view of nearly the earth's entire surface (Johnson et al., 1993). Many researches have been carried out on regional and global land monitoring using NOAA/AVHRR data. The AVHRR-based reflectance in the visible (VIS) and near-infrared (NIR) wavebands and the Normalized Difference Vegetation Index (NDVI) has been used for drought monitoring (Kogan 1994, 1995 and 1997).

Agricultural monitoring is important for estimating for crop productions and detecting agricultural disaster such as droughts and floods. Therefore, the objective of this study is to develop and establish an agricultural monitoring system in East and South East Asia using NOAA/AVHRR data. The system is developed using the changes of up-to-date and normal NDVI from AVHRR data. Using this system, the drought effects on agriculture in China in 2000 year were detected and monitored successfully.

\section{METHOD USED, MATERIALS AND SYSTEM}

\subsection{Methodology}

The NDVI is a very popular parameter from the satellite data. Many researchers have used the NDVI for monitoring global vegetation and climate studies (Kogan 1990, 1994, 1995 and 1997; Los et al., 1994; Ramsey et al., 1995; Tucker et. al., 1983 and 1985; Walker and Mallawaarachchi 1998). The usefulness of the NDVI was highlighted in these researches. In this paper, the changes of up-to-date and normal NDVI from NOAA/AVHRR data are used for detecting and monitoring drought effects on agriculture.

Since there are the cloud areas in NOAA/AVHRR data, for detecting and monitoring drought cloud free satellite data are required. Therefore, to minimize the cloud effect, the largest NDVI value of every pixel is used for the daily and ten-day images. Even using this method, we found that there are too many areas of clouds cover in the daily and weekly images, which find it difficult to detect drought effects on agriculture using these data. On the other hand, monthly data is too long to describe the development of vegetation because morphological changes and leaf appearances occur in short periods.

Accepted on January 12, 2005 
Therefore, in this research, the detection and monitoring of drought effects on each ten-days interval are discussed. The outline of this research method and the algorithm of this research can be found in Fig. 1. The standard NDVI images are created at first. Then, the up-to-date NDVI is calculated just after the ten days and cloud pixels are masked for elimination. Next, the differences between the standard and up-to-date NDVI images are calculated. Lastly, using the differences, it is possible to detect the area and intensity of drought damage on agriculture. The bigger negative difference pixels are listed as drought areas, and the values of difference NDVI show the intensities of the drought damage

\subsection{Satellite Image Database System in Agriculture, Forestry and Fisheries (SIDaB)}

All monitoring must be performed on time, and it needs near-real time data for analyzing and old data as the standard. For this reason, we are now developing Satellite Image Database System (SIDaB) at the Computer Center for Agriculture, Forestry and Fisheries Research. SIDaB gathers raw data of NOAA/AVHRR from three receiving stations in Japan and one station in Thailand, and processes and stores the data. DMSP/OLS data come from National Geophysical Data Center NOAA using networks such as Asia Pacific Advanced Network (APAN). We get NOAA/AVHRR and DMSP/OLS data at near-real time.

The NOAA/AVHRR data are processed and archived Satellite at the Image Database System (SIDaB) in the Computer Center for Agriculture, Forestry and Fisheries Research, Japan (Kodama and Song 2000). In this system, the user can search and download the satellite images freely (http://www.affrc.go.jp/agropedia).

The NOAA/AVHRR data are received at three stations in Japan, Shiogama, Yokohama and Ishigaki, and one station in Thailand, Bangkok belonging to the Asian Institute of Technology (AIT). These data are transmitted using the high-speed network system, and processed at the Computer Center for Agriculture, Forestry and Fisheries Research, Japan. The geometric correction and mosaic are perfomed in a short amount of time using TeraScan software and EWS. The daily, weekly, ten-days and monthly NDVI, MCSST and other datasets are supplied automatically.

\section{RESULTS}

\subsection{Creating the standard NDVI image}

Firstly, we select a suitable period of NOAA/AVHRR data to create the standard NDVI images. When considering climatic periodicity, it appears that the longer time series data are suitable for creating the standard NDVI image. The NOAA/AVHRR data in SIDaB are useful from 1994. However, it is known that clouds and other atmosphere constituents obscure the land surface, reducing NDVI considerably (Goward et al, 1991, 1993; Gutman 1991; Twonshend 1994; Los et al., 1994; Justice and Townshend 1994). Due to the volcanic eruption of Mt.
Pinatubo in 1991, the value of NDVI was depressed for several years by the aerosol in the stratosphere (Stowe $e t$ al., 1991, Gutman and Ignatov, 1995). On the other hand, when considering agriculture, there are annual changes in the vegetation such as extension of arable lands. Therefore, considering these factors, because the atmospheric state is almost stable since 1997, the NOAA/AVHRR data in 1997-1999 are selected for creating the standard NDVI images.

In order to minimize the cloud effects, the ten-days NDVI images are created using the maximum value of every pixel first. Then, the ten-day NDVI images are masked because there are also cloudy pixels even in this method. The cloudy pixels (NDVI $<0$ ) are substituted as the special value areas so that these pixels are eliminated when the averages of NDVI data are calculated. The average values of NDVI data in1997-1999 are that of standard NDVI images.

\subsection{Agriculture Monitoring Using Up-to-Date (2000) NDVI image}

The up-to-date NDVI is calculated near real time and cloud pixels are masked for elimination. Similar to the reason described above, there are also cloudy pixels in the up-to-date ten-day NDVI images even using the maximum value of each pixel for the daily and ten-day images. For these areas, it is impossible to monitor the changes in vegetation. Therefore, these pixels NDVI < 0 ) are substituted as the special value area. When the NDVI image is used, these areas will be eliminated.

The differences between the standard and up-to-date ten-day NDVI images are calculated using formula (1).

$$
\text { NDVI differ }=\text { NDVI } 2000-\text { NDVI ave }
$$

Three categories are made as follows, $>0.1,0.1 \sim 0.1$, and $<-0.1$. Considering the general condition of vegetation growth, $<-0.1$ are listed as having a poor growth of crop than as usual (Fig. 2). The drought areas were estimated using the differences. The large decrease of NDVI pixels were as the drought areas, and the values of the differences show the intensities of drought effects.

\subsection{Detecting and monitoring drought in China}

China is essentially an agricultural country with about 80 percent of its total population engaged in agriculture. It is the biggest developing country, with the one fifth of the world's population. Agricultural damages of natural disaster direct affected to food problem in Asia region. It is important to detect and monitor the changes of crop growth in China. Last 2000, there were heavy droughts in China. In this research, using the early detection system described above, the drought area and intensity are successfully detected and monitored.

Using the agriculture monitoring system described above, the drought risk maps on each ten-day interval in 2000 are created. In this paper, the NDVI difference and intensity in the last ten-day of June and July are described in Fig. 3. In early June, there were areas of drought possibility in Inner Mongolia, China and Mongolia. In 


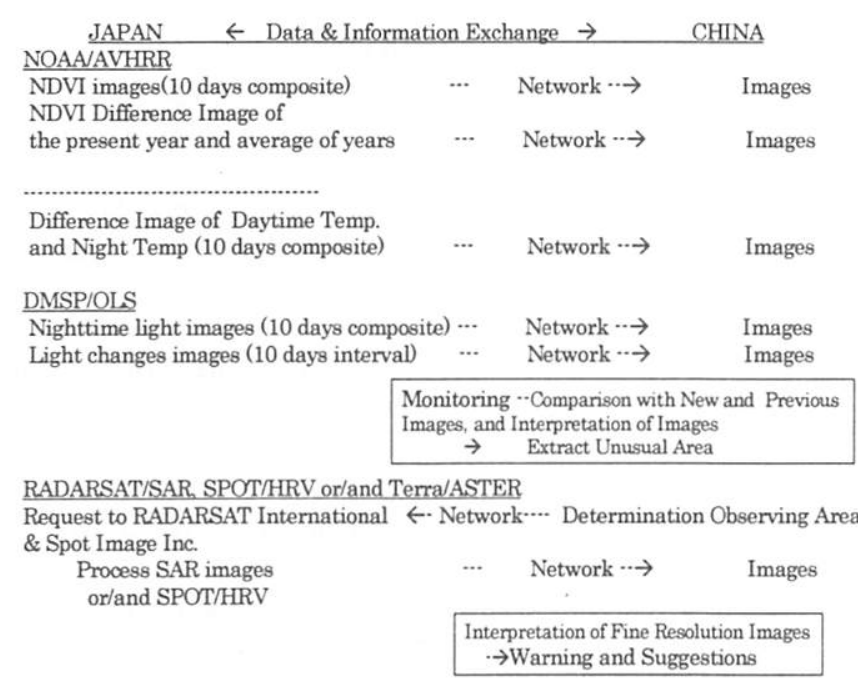

Fig. 1 The total study plan of agricultural monitoring using satellite data in East Asia.

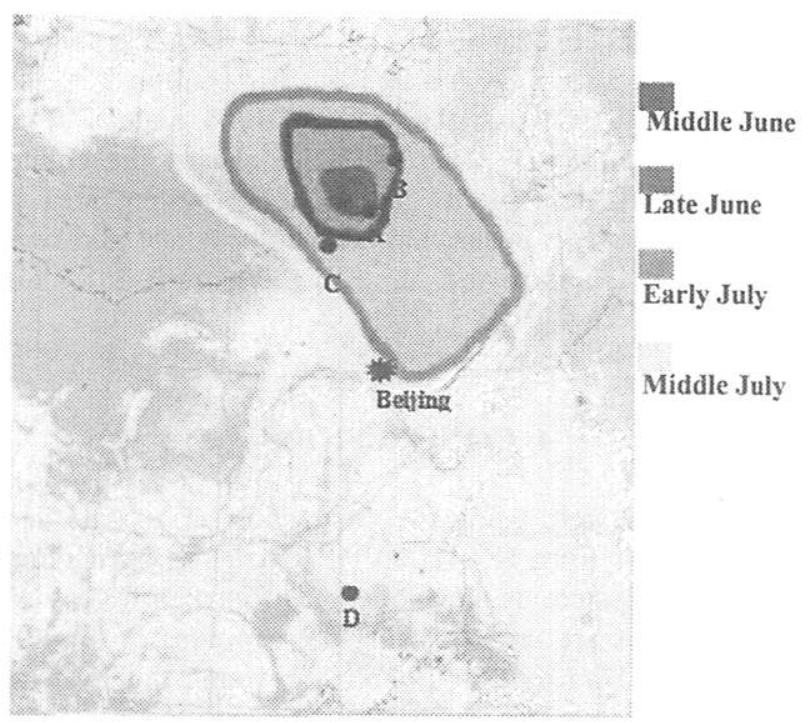

Fig. 3 Drought possibility area in north China 2000 made by the agricultural monitoring system using NOAA/AVHRR
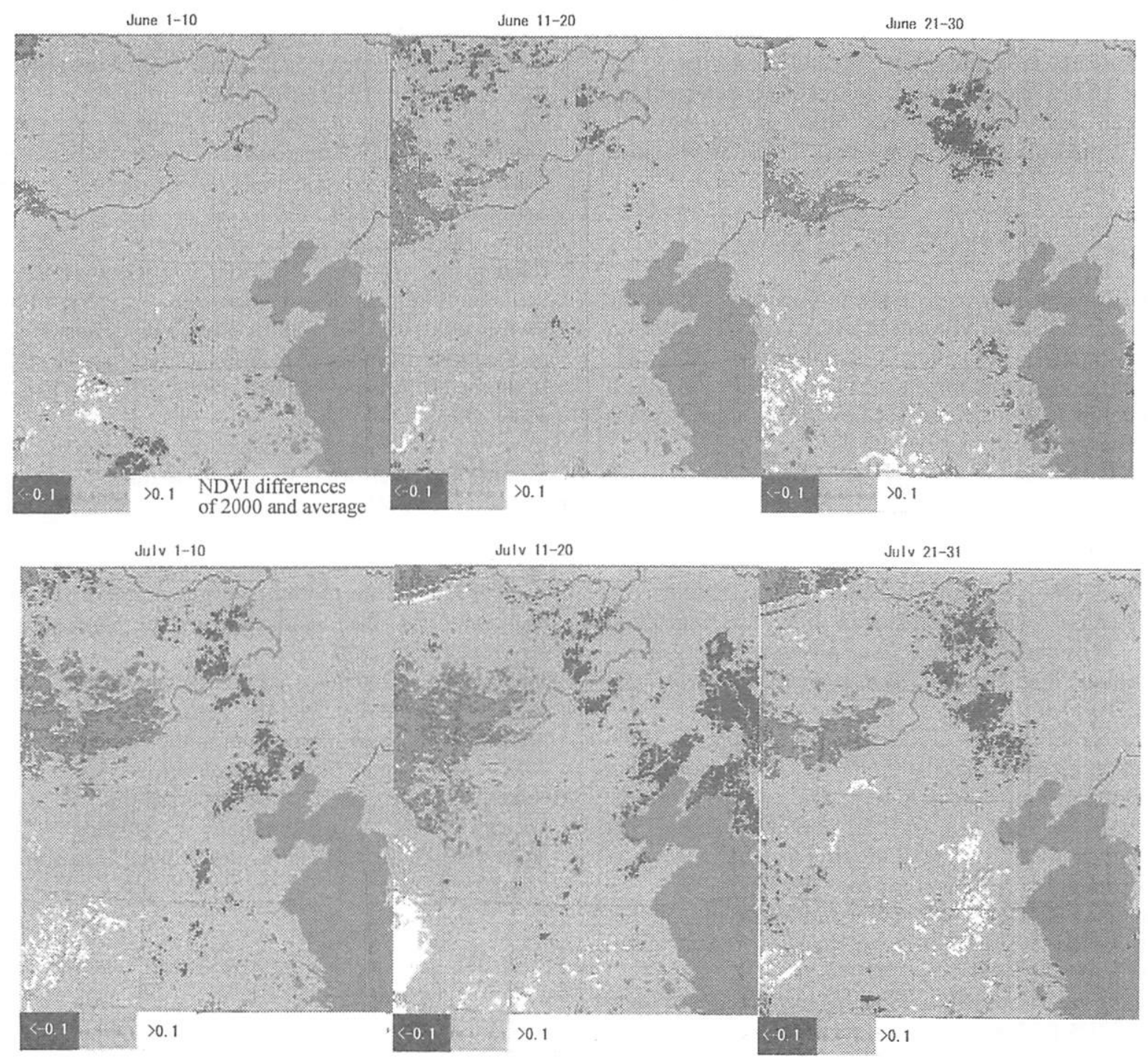

Fig. 2 NDVI differences Image of 2000 and average of years 1997 - 1999 
Late June and July the area extended all direction. NDVI profiles are checked (A) to (D) in Fig.3. According to these. Forest Steppe (A and B) has a big peak in July and Desert Steppe (C) has a significant high plateau from June to September. We can easily understand the effects of drought at these plots. The two crop system area in China (D) has two peaks that are winter wheat and rice. At the D, it is almost the same for 2000 as it is for the three-year average.

\section{CONCLUSIONS}

In this research, using the changes of up-to-date and normal NDVI from NOAA/AVHRR data, an agriculture monitoring system is developed. The standard ten-day NDVI images are created using the averages of ten-day cloud free NDVI data in 1997-1999. Using this system, we are able to make a drought risk map. The map is created using the differences between the up-to-date ten-day NDVI images and the standard NDVI images. More negative difference pixels (difference NDVI $<-0.1$ ) are listed as the drought risk areas. The drought risk maps in China last year are discussed as an example. Compiling the analyses of characteristics of NDVI profiles and meteorological precipitation data, the drought effects on agriculture in 2000 are detected and monitored successfully. It has been shown that this system is possible and useful for detecting drought areas.

\section{ACKNOWLEDGMENTS}

This research is a part of the project of Asia Pacific Network for Disaster Mitigation using Earth Observation Satellite (ANDES), financially supported by ACT-JST: Research and Development for Applying Advanced Computational Science and Technology of Japan Science and Technology Corporation.

\section{REFERENCES}

Goward, S. N., Markham, B., Dye, D. G., Dulaney, W. And Yang, J., 1991, Normalized difference vegetation index measurements from the Advanced Very High Resolution Radiometer. Remote Sens. Environ., 35, 257-277.

Goward, S. N., Dye, D. G., Turner, S. and Yang, J., 1993, Objective assessment of the NOAA Global Vegetation Index data product. Int. J. Remote Sens., 14, 3365-3394. Goward, S. N., Turner, S. Dye, D. G., and Liang, S., 1994, The University of Maryland improved global vegetation index product. Int. J. Remote Sens., 15, 3365-3397.

Gutman, G. G., 1991, Vegetation indices from AVHRR data: An update and future prospects. Remote Sens. Environ., 35, 121-136.

Gutman, G. and A. Ignatov, 1995: Global land monitoring from AVHRR: Potential and limitations. Int. J. Remote Sens., 16, 2301-2309
Johson, G. E., Achutuni, V. R., Thiruvengadachari, S. and Kogan, F. N., 1993. The role of NOAA satellite data in drought early warning and monitoring. In: Wilhite, $D$. A. Ed., Drought Assessment, Management, and Planning: Theory and Case Studies. Kluwer Academic, 31-49.

Justice, C. O. And Townshend, J. R. G., 1994, Data sets for global remote sensing: Lessons learnt. Int. J. Remote Sens., 15, 3621-3639.

Kodama, M And Song, X., 2000, A new remote sensing database system in Ministry of Agriculture, Forestry and Fisheries, Japan. $51^{\text {st }}$ International Astronautical Congress. 2-6 Oct. 2000 (Brazil: Rio de Janeiro).

Kogan, F. N., 1990, Remote sensing of weather impacts on vegetation in non-homogeneous areas. Int. J. Remote Sens., 11, 1405-1419.

Kogan, F. N., 1994, Application of vegetation index and brightness temperature for drought detection. Adv. Space Res., 15 (11), 91-100.

Kogan, F. N., 1995, Droughts of the late 1980s in the United States as derived from NOAA polar orbiting satellite data. Bull. Amer. Meteor. Sco., 76, 655-668.

Kogan, F. N., 1997, Global drought watch from space. American Meteor. Sco., pp.16

Kogan, F. N., AND Sullivan, J., 1993, Development of global drought watch system using NOAA/AVHRR data. Adv. Space Res., 13 (5), 219-222.

Los, S. O., Justice, C. O., and Tucker, C. J., 1994, A global 1 by 1 NDVI data set for climate studies derived from the GIMMS continental NDVI data. Int. J. Remote Sens., 15, 3493-3518.

Ramsey, R. D., Falconer, A., and Jensen, J. R., 1995. The relationship between NOAA/AVHRR NDVI and ecoregions in Utah: Remote Sens. Environ., 53, 188-198. Townshend, J. R. G., 1994, Global data sets for land applications from the Advanced Very High Resolution Radiometer: An introduction. Int. J. Remote Sens. 15, 3319-3332.

Stowe, L. L., R. M. Carey, and P. P. Pelegrino, 1992, Monitoring the Mt. Pinatubo aerosol layer with NOAA-11 AVHRR data, Geophys. Res. Lett., 19, 159-162.

Tucker, C. J., Vanpraet, C., Boerwinkel, E., and Gatson, A., 1983, Satellite remote sensing of total dry matter production in the Senegalese Sahel. Remote Sens. Environ. 13, 461-474.

Tucker, C. J., Vanpraet, C. L., Sharman, M. J., and Van Ittersum, G., 1985, Satellite remote sensing of total herbaceous biomass production in the Senegalese Sahel: 1980-1984. Remote Sens. Environ. 17, 233-249.

Walker, P. A., and Mallawaarachchi, T., 1998, Disaggregating agricultural statistics using NOAA/AVHRR NDVI. Remote Sens. Environ., 63, 112-125. 